\title{
The Impact of Task Complexity on EFL Learners' Writing Production across Gender
}

\author{
Mahgoub Kamel Mahmoud Mohammad, Nik Aloesnita Alwi
}

\begin{abstract}
The current study investigates the impact of task complexity on EFL learners' writing production across gender. Task complexity is the inherent cognitive demands of the tasks imposed on the learners by the structure of the tasks. In this study, task complexity is investigated along the resource-dispersing variables of pre-task planning time, post-task editing time and prior knowledge across gender. This study tries to intertwine the concepts of task complexity and sociolinguistics (i.e. gender differences). This study was aimed to find out the effect of task complexity across the variable of gender of EFL learners' writing production which has been measured in terms of CAF i.e. complexity, accuracy and fluency. Therefore, the linguistics properties of 160 essays from EFL learners $(80$ males \& 80 females) were analyzed on the CAF. The participants were selected from a homogenous group of EFL learners. A web-based syntactical/lexical text analysis software was employed to measure the CAF of the EFL learners' essays. This can provide useful information in field of foreign language learning for language planners, curricula designers, and teachers. Should this be done, it can contribute to improving EFL undergraduate students' ability to a level of writing competence that is more likely to be satisfactory. The findings of the study indicated statistically significant support for Robinsons' Hypothesis. Increasing resource-dispersing complexity by removing planning time, editing time and prior knowledge negatively affected the CAF of writing of both genders, male and female. In terms of gender, female groups significantly outperformed their male counterparts in most of the overall CAF writing scores along resource-dispersing of pre-task planning time, post-task editing time and prior knowledge in both low complexity and high complexity writing tasks.
\end{abstract}

Keywords: Task Complexity, Resource-Dispersing, Writing Production, Gender differences.

\section{INTRODUCTION}

During the last few decades many theories about gender differences in language have appeared. Many linguists tried to explain different approaches to the use of language by members of two genders. Studies have suggested that men and women tend to favor distinct language features in expressing themselves (Lakoff 1975, Waskita, 2008, Matei, 2011, Subon, 2013, and Shirzad and Jamali, 2013). Lakoff (1975) revealed that women used linguistic features that reinforced their subordination. She further revealed that they were inclined to use some specific language features, such as lexical hedges, tag questions, empty adjectives, intensifiers, and emphatic stress. Some studies have extensively explored

Revised Version Manuscript Received on April 19, 2019.

Mahgoub Kamel Mahmoud mohammad, Universiti Malaysia Pahang, Centre for Modern Languages \& Human Sciences, Universiti Malaysia Pahang, 26300 Gambang, Pahang, Malaysia.

Nik Aloesnita Alwi, Universiti Malaysia Pahang, Centre for Modern Languages \& Human Sciences, Universiti Malaysia Pahang, 26300 Gambang, Pahang, Malaysia. how gender differences influence written language (Shirzad and Jamali, 2013, and Waskita, 2008).

Research noting gender differences in academic achievement has been discussed in a variety of education and psychology journals. In general, girls mature faster and master verbal and motor skills (e.g., drawing) more rapidly than boys (Eggen \& Kauchak, 2013). The study of gender differences in language production is important for several reasons. One reason is its relevance to psycholinguistics. It has been previously established that individual differences in maintaining attention on the production processes become especially apparent when a simultaneous second task also requires intentional resources (Jongman, Roelofs \& Meyer, 2014).

While the issue of reading is received greater attention, there is a growing body of evidence that males and females also differ in writing ability (Camarata \& Woodcock, 2006; Reynolds, Scheiber, Hajovsky, Schwartz, \& Kaufman, 2015; Scheiber, Reynolds, Hajovsky, \& Kaufman, 2015). Reynolds et al. (2015) noted that the issue of gender differences in writing skills has been overlooked. This study delved into differences in performance, if any, between boys and girls in terms of task complexity.

Specifically, the current study addresses the following main research questions:

a) What is the effect of high task complexity on EFL learners' writing production across gender?

b) What is the effect of task complexity along the resource-dispersing variable of \pm planning time on EFL learners' writing production across gender?

c) What is the effect of task complexity along the resource-dispersing variable of \pm post-task editing time on EFL learners' writing production across gender?

d) What is the effect of task complexity along the resource-dispersing variable of \pm prior knowledge on EFL learners' writing production across gender?

\section{OBJECTIVES}

This research aims to study the impact of task complexity on gender differences of EFL learners' writing production which has been measured in terms of CAF i.e. complexity, accuracy and fluency. The International high school students' performance of cause and effect essay writing task is taken as the population of the research. The task complexity was investigated along certain resource-dispersing variables, whereas resource-directing variables were be investigated in this study. 
The theoretical model developed by Peter Robinson (2001), i.e. Cognition Hypothesis was applied in this study.

\section{METHODOLOGY}

The study was conducted on the ninth graders in four international schools in Riyadh City. At the time of data collection, the participants were studying Prentice Hall Writing Coach, by Pearson Education, Jeff Anderson and Kelly Gallagher (2012). Prior to the current research, they had studied how to write cause and effect essay. For the purpose of this study, a sample of 160 high school students (80 males and 80 females) following an American curriculum participated to find answers to the research questions. A Cause and effect essay writing task with different complexity levels was used as a data collection instrument to provide an in-depth information to uphold the validity of findings. This thesis utilised four essay-writing contexts; a) Writing Task, b) Writing Task+10 min pre-task planning time, c) Writing Task +10 minutes post-task editing time, and d) Writing Task+ prior knowledge. Context (a) is a high complexity task, whereas contexts b, c, and d are low complexity task. Each context was assigned to a certain group according to table 1.1.

Table 1.1 Research Contexts

\begin{tabular}{|c|c|}
\hline Groups & Context \\
\hline Male Students & High Complexity Task \\
\hline Group Code: (G1M) & Task Code: M1HC \\
\hline Female Students & High Complexity Task \\
\hline Group Code: (G1F) & Task Code: F1HC \\
\hline Male Students & Task+10 min pre-task planning time \\
\hline Group Code: (G2M) & Task Code: M2PT \\
\hline Female Students & Task +10 min pre-task planning time \\
\hline Group Code: (G2M) & Task Code: F2PT \\
\hline Male Students & Task +10 minutes post-task editing time \\
\hline Group Code: (G3F) & Task Code: M3ET \\
\hline Female Students & Task+10 minutes post-task editing time \\
\hline Group Code: (G3M) & Task Code: F3ET \\
\hline Male Students & Task+ prior knowledge (a familiar area) \\
\hline Group Code: (G4M) & Task Code: M4PK \\
\hline Female Students & Task+ prior knowledge (a familiar area) \\
\hline Group Code: (G4F) & Task Code: F4PK \\
\hline
\end{tabular}

Key: $\mathrm{G}=$ Group, $\mathrm{M}=$ Masculine, $\mathrm{F}=$ Feminine, $\mathrm{HC}=$ High Complexity, $\mathrm{PT}=$ Planning time, $\mathrm{ET}=$ Editing time, $\mathrm{PK}=$ Prior Knowledge.

Before stage 1 starts, the researcher initially handed out a survey that was designed to gather personal information about each participant. During stage 1, students were given an IELTS task 2 essay to write. The aim of this task is to make sure that all the groups are homogeneous. The task was analysed according to the same CAF measures used in stage 2 i.e. using Lu (2012)'s Lexical and syntactical Complexity Analyzer and accuracy and fluency measures (see Data and Statistical analysis section). During Stage 2, the writing task was assigned to all groups; however, the extra variables of pre-task planning time, post-task editing time and prior knowledge were added to Cohorts 2, 3 and 4 respectively. During the 10 minutes pre-task planning time, participants were encouraged to take notes and plan for the task during this time, but they were not allowed to begin writing the tasks until the 10 minutes planning time was completed. Subsequently, the participants had 40 minutes to complete each task, during which they were able to refer to the notes they had taken during the planning time. During the 10 minutes post-task editing time allowed for each task, participants were given a red pen, which was a different colour to the pens used in the writing of the tasks. Subsequently, the participants were instructed to edit the work that they had just completed. As for the Prior knowledge (a familiar area) groups, they were instructed for 4 sessions' time about the water pollution cause and effect on the environment. The participants of this group watched videos, listened to audios, read articles and invited to do research through the web. They were only told about the task after instruction sessions were done by teachers.

\section{RESULTS}

The findings from this thesis, when viewed through the lens of Robinsons' Hypothesis, showed statistically significant support for Robinsons' Hypothesis. Increasing resource-dispersing complexity by removing planning time, editing time and prior knowledge negatively affected the production of writing. Alternatively, decreasing complexity along the resource-dispersing variables of planning time, editing time and prior knowledge, which facilitated complex language production. More complex tasks along resource-directing dimension pushed greater development of complexity and accuracy of language production whereas fluency was negatively affected. In contrast, resource-dispersing dimensions (e.g., including planning time, editing time, and prior knowledge), accuracy, fluency and complexity of production decreased when task is made complex along resource dispersing dimension. Besides, study concluded that there is statistically significant difference between males and females in terms of writing production along task complexity. Increasing resource-dispersing complexity by removing planning time, editing time and prior knowledge negatively affected the CAF of writing of both genders, male and female. In terms of gender, female groups significantly outperformed their male counterparts in most of the overall CAF writing scores along resource-dispersing of pre-task planning time, post-task editing time and prior knowledge in both low complexity and high complexity writing tasks

\section{CONCLUSION}

The study of task complexity and writing is a relatively under researched area, and the results from this thesis have shown that there is a rich vein of research to be mined, with potential contributions to acquisition, pedagogy, and a potential rethinking of the dialectic relationship between competing theories on complexity and output. The positive aspects form RQ have shown that under the correct conditions, students can benefit from increases in cognitive task complexity. 
However, the results from this thesis have shown that the focus on complexity in writing production is potentially very detailed and difficult, with much consideration needing to be placed into the alignment of contributing variables if students are going to produce complex language under cognitive duress using limited attentional resources. For teachers and researchers to be able to control positive outcomes, much more work will be required to be able to remove some of the random nature of the current work.

\section{ACKNOWLEDGEMENTS}

It is a good opportunity to express my gratitude to the people who have been instrumental in the successful completion of this thesis. I would like to gratefully and sincerely thank my supervisor Dr. Nik Aloesnita Alwi for her guidance, and most importantly, her patience during my research.

\section{REFERENCES}

1.Ai,H.(2016a).Web-basedL2syntacticalcomplexityanalyzer.Retrieve dfromhttp://aihaiyang.com/software/12sca/

2.Ai,H.(2016b).Web-basedlexicalcomplexityanalyzer.Retrievedfromh ttp://aihaiyang.com/software/lca/

3.Eggen,P.,\&Kauchak,D.(2013).Educationalpsychology:Windowsonc lassrooms(9thEd.).Boston,MA:Pearson.

4.Hammad,E.A.(2016).PalestinianUniversitystudents'problemswithE FLessaywritinginaninstructionalsettingTeachingEFLWritinginth e21stCenturyArabWorld(pp.99-124):Springer.

5.Jiaxin,X.I.N.G.(2015).TheeffectsofincreasingtaskcomplexityonEFL1 earners'writingperformance.StudiesinLiteratureandLanguage, 11 (4),34-39.doi:10.3968/7711

6.Lakoff,R.(1975).Languageandwoman'splace.NewYork:HarperColo phon.

7.Lee,J.A.C.,andAlOtaiba,S.(2015).Socioeconomicandgendergroupdi fferencesinearlyliteracyskills:Amultiple-groupconfirmatoryfacto ranalysisapproach.EducationalResearchandEvaluation,21(1),4059.

8.Lintunen,P.,andMäkilä,M.(2014).Measuringsyntacticcomplexityins pokenandwrittenlearnerlanguage:Comparingtheincomparable?R esearchinLanguage, 12(4),377-399.doi:10.1515/rela-2015-0005

9.Matei,M.(2011).Theinfluenceofageandgenderontheselectionofdisco ursemarkersincasualconversations.BulletinoftheTransilvaniaUni versityofBraşov.SeriesIV:PhilologyandCulturalStudies,4(53),21 3-220.

10.Mazgutova,D.,andKormos,J.(2015).Syntacticandlexicaldevelopme ntinanintensiveEnglishforacademicpurposesprogramme.Journal ofSecondLanguageWriting,29,3-15.

11.Ortega,L.(2015).SyntacticcomplexityinL2writing:Progressandexpa nsion.JournalofSecondLanguageWriting,29,82-94.

12.Pasaribu,T.A.(2017)Maleandfemalestudents'useoftextualdiscourse markersinwritingacademicessays.JournalofLanguageandLiteratu re, $17(1)$.

13.Reynolds,M.,Scheiber,C.,Hajovsky,D.,Schwartz,B.,andKaufman, A.(2015).Genderdifferencesinacademicachievement:Iswritingan exceptiontothegendersimilaritieshypothesis?TheJournalofGeneti cPsychology,176(4),211-234.

14.Robinson,P.(2011b).Secondlanguagetaskcomplexity, thecognitionh ypothesis, languagelearning, andperformance.InP.Robinson(Ed.), Secondlanguagetaskcomplexity:Researchingthecognitionhypoth esisoflanguagelearningandperformance(pp.337).Amsterdam, The Netherlands:JohnBenjaminsPublishingCompany.

15.Robinson,P.(2015).Thecognitionhypothesis,secondlanguagetaskde mands, andtheSSARCmodelofpedagogicsequencing.InM.Bygate (Ed.),DomainsanddirectionsinthedevelopmentofTBLT(pp.87-1 21).Amsterdam, TheNetherlands:JohnBenjaminsPublishingCom pany.

16.Scheiber,C.,Reynolds,MatthewR.,Hajovsky,D.B.,Kaufman,A.S.(2 015)Genderdifferencesinachievementinalarge,nationallyrepresen tativesampleofchildrenandadolescents.PsychologyinSchools,52( 4),335-348

17.Seyyedrezaie,Z.S.andVahedi,V.S.(2017).Projectinggenderidentityt
hroughmetadiscoursemarking:Investigatingwriters'stancetaking nwrittendiscourse.IndonesianJournalofAppliedLinguistics, 6(2),3 $01-310$.

18.Sharma,V.K.(2015).HowdoproductiveskillsofSaudistudentsaffectE FLlearningandteaching?AsianJournalofHumanitiesandSocialSci encesJHS,3(2),91-99.

19.Shirzad\&Jamali.(2013).GenderdifferencesinEFLacademicwriting. NewYork:LambertPublishing.

20.Subon,F.(2013)Genderdifferencesintheuseoflinguisticformsinthesp eechofmenandwomenintheMalaysiancontext.IOSRJournalofHu manitiesAndSocialScience(IOSR-JHSS),13(3),67-79.

21.Waskita,D.(2008).Differencesinmen'sandwomen'sESLacademicw ritingattheUniversityofMelbourne.JurnalSocioteknologi,7(14).

22.Yeganeh,M.T.andGhoreyshi,S.M.(2015).Exploringgenderdifferenc esintheuseofdiscoursemarkersinIranianacademicresearcharticles. Procedia-SocialandBehavioralScience,192,684-689.

\section{AUTHORS PROFILE}

Mahgoub Kamel Mahmoud mohammad, Universiti Malaysia Pahang, Centre for Modern Languages \& Human Sciences, Universiti Malaysia Pahang, 26300 Gambang, Pahang, Malaysia.

Nik Aloesnita Alwi, Universiti Malaysia Pahang, Centre for Modern Languages \& Human Sciences, Universiti Malaysia Pahang, 26300 Gambang, Pahang, Malaysia. 